\title{
En defensa de una sociedad intercultural. Presupuestos hermenéuticos del análisis socio- -político del caso Quebec en Building the Future, de G. Bouchard y Ch. Taylor
}

\author{
Advocacy of an intercultural society. Hermeneutic estimates \\ of the socio-political analysis of the Quebec case in Building \\ the Future by G. Bouchard and Ch. Taylor
}

\section{Em defesa de uma sociedade intercultural. Suposições} hermenêuticas da análise sociopolítica do caso Quebec em Building the Future, de $\mathrm{G}$. Bouchard e CH. Taylor

Mg. Víctor Páramo Valero ${ }^{1}$

Recibido: 17/06/2014 - Aceptado: 10/09/2014

\begin{abstract}
Resumen
En este artículo realizamos, en primer lugar, un análisis de la concepción hermenéutica de la comprensión intercultural en H.-G. Gadamer y Ch. Taylor. Clarificamos, en segundo lugar, la teoría social de la interculturalidad que Taylor desarrolla junto a G. Bouchard en un Informe titulado Building the Future. The Time of Reconciliation. Nuestro objetivo es mostrar cuáles son los principales presupuestos hermenéuticos de la propuesta socio-política de este Informe.
\end{abstract}

Palabras clave: Gadamer - Taylor - hermenéutica - comprensión - interculturalidad.

Abstract

In this paper we firstly present an analysis of the hermeneutic conception of intercultural understanding in H.-G. Gadamer and Ch. Taylor. Secondly, we clarified the social theory of interculturality developed by Taylor and

1 Licenciado en Filosofía. Magíster en Ética y Democracia. Doctorando en Filosofía. Universitat de València, España. vicpava@gmail.com 
G. Bouchard in a report entitled Building the Future. The Time of Reconciliation. Our goal is to show the main hermeneutical estimations of the socio-political proposal in this report.

Key words: Gadamer - Taylor - hermeneutics - understanding - interculturality.

\section{Resumo}

Neste artigo, em primeiro lugar, realiza-se uma análise da concepção hermenêutica da compreensão intercultural em H-G. Gadamer e CH. Taylor. Esclarecemos, em segundo lugar, a teoria social da interculturalidade que Taylor desenvolve juntamente com G. Bouchard num relatório titulado Building the Future. The Time of Reconciliation. Nosso objetivo é mostrar quais são as suposições hermenêuticas da proposta sociopolítica deste relatório.

Palavras-chave: Gadamer - Taylor - Hermenêutica - Compreensão Interculturalidade. 


\section{Introducción}

La noción de comprensión que Hans-Georg Gadamer (el principal representante de la hermenéutica filosófica del siglo pasado) desarrolla en su obra principal, Verdad y método, ha influido en Charles Taylor. La fundamentación de la noción de comprensión intercultural ${ }^{2}$ constituye en su planteamiento un paso previo a la defensa teórica y práctica de la interculturalidad. La exposición del contenido de dicha noción de comprensión que realizamos en la primera parte del presente trabajo sirve para otorgar legitimidad al análisis socio-político y a la promoción misma de la interculturalidad frente al etnocentrismo y al relativismo (posiciones que también se han adentrado en el campo de la política, como señala R. Rorty ${ }^{3}$ ). Si arrojamos luz desde la hermenéutica sobre el problema de si es posible la comprensión intercultural podremos disponer de una base sólida desde la cual argumentar a favor de las

2 Gadamer no emplea la noción de "comprensión intercultural". En nuestra lectura conjunta de Verdad y método (y en particular de las secciones dedicadas a exponer su concepción de la comprensión) y del trabajo de Taylor "Comprensión y etnocentrismo" estableceremos un vínculo (que creemos encontrar en la propia propuesta de Taylor, por su empleo de la metáfora gadameriana de la fusión de horizontes para explicar cómo es posible la intercomprensión entre individuos pertenecientes a culturas distintas, que tienen marcos de comprensión distintos) entre la noción hermenéutica de comprensión en Gadamer, (que no hace en ningún momento referencia explícita a problemas relativos al multiculturalismo, pero que sí habla del papel del otro (en general, no el otro cultural) en la comprensión. La idea gadameriana de que "el otro pueda tener razón" puede ser aplicada al problema de la comprensión entre individuos que poseen marcos culturales de comprensión distintos: que el otro pueda tener razón significa en el contexto de la antropología filosófica y cultural de Taylor, en el trabajo citado, que podemos ponernos en la posición del otro y comprendernos a nosotros mismos desde sus términos. Es decir, podemos comprendernos en los términos de la autocomprensión del otro cultural. Esta idea, que sí es de Taylor, congenia a la perfección con la de Gadamer sobre la concesión de la palabra al otro para que nos interpele y de que nuestros propios horizontes de comprensión (que en el contexto de este trabajo significarán horizontes culturales de comprensión, es decir, los horizontes de comprensión que marca nuestra propia cultura) pueden ser comprendidos no solo desde nuestra propia posición sino también desde la del otro (sin abandonar completamente la nuestra). Al mismo tiempo, y como veremos en su momento, la metáfora de la fusión de horizontes se puede aplicar a problemas relativos a si es posible o no la comprensión entre individuos con marcos culturales distintos: la comprensión entre tales individuos es posible solo cuando los horizontes de comprensión de cada uno se fusionan.

3 Cf. RORTY. Richard, Forjar nuestro país, Paidós, Barcelona, 1995, pág. 74. 
actuaciones sociales y políticas que promueven la interculturalidad, tal y como hacen Gérard Bouchard y el propio Taylor en un Informetitulado Building the Future. A Time of Reconciliation, el cual presenta los resultados de las investigaciones realizadas por la Comisión que lleva el nombre de ambos autores.

La legitimidad de nuestro intento de correlacionar hermenéutica y teoría socio-política desde la perspectiva de Taylor reside en la conexión que el propio pensador canadiense ha establecido entre ambas disciplinas en sus obras dedicadas a estudiar el problema de la interculturalidad ${ }^{4}$.

La hermenéutica filosófica y la teoría socio-política sobre el multiculturalismo son dos ramas de investigación que se complementan a la hora de estudiar el problema de si es posible o no la interculturalidad. Esto puede percibirse en el pensamiento de Taylor.

La tesis del presente trabajo afirma que la justificación filosófica de la perspectiva que Taylor adopta en Building the Future se encuentra en sus escritos sobre hermenéutica, y en particular en su reformulación de la metáfora gadameriana de la "fusión de horizontes".

La teoría de la comprensión del "otro" que forma parte del núcleo de la hermenéutica de Gadamer tiene un gran potencial para pensar problemas propios de la filosofía de la cultura y la antropología filosófica. Aunque la hermenéutica gadameriana no es estudiada habitualmente dentro de estas dos ramas filosóficas, la perspectiva que ha elaborado puede ser introducida en ambas para arrojar luz sobre problemas en torno a los cuales se ha debatido en las últimas décadas. La hermenéutica, como vamos a comprobar, puede ser empleada para pensar problemas relativos al multiculturalismo, etnocentrismo y relativismo cultural.

4 Su ensayo más célebre sobre este problema, "El multiculturalismo y la política del reconocimiento", no será estudiado en el presente trabajo, ya que, como ha señalado acertadamente M. Walzer, en él Taylor adopta una perspectiva política que atiende principalmente a cuestiones relacionadas con el debate, todavía en activo en Estados Unidos, en torno a qué modelo de liberalismo es el más acertado ( $y$, en consecuencia, qué concepción de los derechos y la comunidad política es la más acertada). 
El problema del "otro" es uno de los principales problemas filosóficos que hallamos en Building the Future. De ello dan cuenta las siguientes palabras:

"De acuerdo con el espíritu de la reciprocidad, la interculturalidad hace un fuerte hincapié en la Interacción, en particular en las acciones intercomunitarias, con vistas a vencer los estereotipos y desactivar el miedo o el rechazo del Otro" ${ }^{5}$.

Nos proponemos mostrar el trasfondo hermenéutico de esta propuesta de Bouchard y Taylor que promueve la interculturalidad. Para ello, nos remontaremos primero a los fundamentos hermenéuticos de la comprensión que Taylor expone en sus ensayos "La interpretación y las ciencias del hombre" y "Etnocentrismo y comprensión". No son los únicos artículos que Taylor dedica a cuestiones de hermenéutica filosófica, pero son sin duda dos de los más afines al problema de la comprensión del otro, y su estudio nos permitirá desvelar el trasfondo hermenéutico de la propuesta socio-política de Taylor y Bouchard en el mencionado Informe.

Algunos autores han reconstruido la teoría hermenéutica que se encuentra en la base de la filosofía política y moral de Ch. Taylor ${ }^{6}$. En este ensayo nos proponemos una tarea menor pero afín a ésta. Los problemas morales, sociales y político-culturales emergentes en Quebec y puestos de manifiesto en Building the Future son considerados por Taylor a la luz de la hermenéutica de Gadamer, a la cual no se alude explícitamente en el Informe Bouchard-Taylor pero que, como veremos, guía su propia visión de tales problemas.

Podemos hablar de "hermenéutica intercultural" para referirnos a aquella parte de la hermenéutica filosófica que se ocupa del estudio de si es posible la comprensión entre dos o más individuos procedentes de culturas distintas. No considera el problema de la intercomprensión

5 BOUCHARD, Gérard, \& TAYLOR, Charles. Building the Future. Abridged Report, Bibliothèque et Archives nationales du Quebec, Quebec, 2008, pág. 46.

6 Cf. GRACIA, Javier. Antropología filosófica en Charles Taylor. Perfil hermenéutico del ser humano, EAE, Saarbrücken, 2011. 
en general, sino el caso particular de los individuos que se encuentran o han sido formados en culturas distintas.

Taylor no necesita aludir en Building the Future a las bases hermenéuticas de su concepción del encuentro intercultural ${ }^{7}$, ni tampoco a los autores en que se ha basado para elaborarla. Primero, porque el Informe es un escrito dirigido a un público amplio, es decir, no está dirigido a un grupo de especialistas en filosofía, sociología o política, y por lo tanto el lenguaje empleado y el modo de presentar los resultados de la investigación no podía ser otro que un escrito claro y conciso ${ }^{8}$. Segundo, porque el Informe debía exponer -tal y como solicitaba el gobierno9 el cual promovió la formación de la Comisión que ha llevado a cabo la investigación sobre los conflictos multiculturales en Quebec- únicamente los resultados alcanzados de la investigación así como una propuesta sólida con que hacer frente a tales conflictos ${ }^{10}$.

De modo que las bases hermenéuticas a las que nos referimos no podían ser expuestas en dicho Informe. En algunas secciones de este escrito se hace evidente que tales bases se dan por supuestas, como podremos comprobar en el caso particular de la metáfora de la fusión de horizontes, que sirve para explicar cómo es posible la comprensión $y$, en particular, la comprensión intercultural: esta comprensión se presupone como posible en el Informe, ya que la posibilidad de esta comprensión se ha demostrado, primero, en Verdad y método en el caso

7 Cf. GRACIA, Javier. "El encuentro intercultural en la hermenéutica de Charles Taylor", Diálogo Filosófico, № 64, 2005, págs. 77-94.

8 Con frecuencia los autores introducen recuadros y tablas en los que se refleja la información más relevante.

9 Como veremos, el gobierno respondió de distintos modos a la problemática situación del multiculturalismo en Quebec que se ha originado en los últimos años e intentará mostrar el porqué de que los ciudadanos quebequenses perciban negativamente las "prácticas de armonización (accomodation)". Estos ciudadanos piensan que tales prácticas están dificultando el mantenimiento del orden social y poniendo en cuestión los valores básicos de una sociedad democrática.

10 Los resultados no fueron tan negativos como se esperaban, como indican al comienzo los autores del Informe: la crisis en la que se encontraba la sociedad quebequenses -lo cual había motivado la elaboración de la investigación a cargo de la Comisión Bouchard-Taylor- no era tan profunda como al principio se había creído. 
de la comprensión en general y, segundo, en los artículos de Taylor mencionados en el caso particular de la comprensión intercultural. Frente a teorías como el etnocentrismo o el relativismo, la hermenéutica intercultural defiende que la comprensión entre individuos de distintas culturas es posible. No existe incompatibilidad entre los distintos marcos de comprensión que constituyen las culturas. Taylor, como representante de esta hermenéutica, da por hecho que el acercamiento entre culturas es algo que contribuirá a que se comprendan mejor entre sí. Esta asunción es fundamental y tendremos que mostrar, como hemos señalado, en qué se basa.

En su Introducción a Gadamer, J. Grondin señala:

"Todo tiene su razón, cuando uno se sitúa en la perspectiva del otro y tiene en cuenta sus razones. La proposición presupone la propia finitud y la apertura hacia el otro. El alma de la hermenéutica, como dirá a menudo el Gadamer de los últimos tiempos, consiste en que el otro pueda tener razón"111.

Que el otro pueda tener razón significa: que nosotros podamos no tener razón. Esta es una de las claves de la hermenéutica dialógica de Gadamer ${ }^{12}$. Sin duda es al mismo tiempo una de las claves de la hermenéutica intercultural que se deriva de la hermenéutica del otro que Taylor construye partiendo de Gadamer. Conceder que el otro pueda tener razón y que "nosotros" no la tengamos quiere decir: al entender al otro no tenemos -desde nuestro horizonte cultural- por qué negarnos a nosotros mismos, no tenemos por qué negar el horizonte cultural en el que nos encontramos y desde el cual comprendemos al otro en nuestros propios términos (en los "términos de nuestra autocomprensión"13). Comprender al otro no implica negar nuestro horizonte cultural, sino fusionarlo con el suyo, en el sentido de ampliar o "ganar" un horizonte nuevo, que no es

11 GRONDIN, Jean. Introducción a Gadamer, Herder, Barcelona, 2001, pág. 34.

12 Cf. al respecto DOMINGO MORATALLA, Agustín. El arte de poder no tener razón. La hermenéutica dialógica de H.-G. Gadamer, Universidad Pontificia, Salamanca, 1991.

13 TAYLOR, Charles. "Comprensión y etnocentrismo", en La libertad de los modernos, Amorrortu, Madrid, 2005, pág. 214. 
sino un reforzamiento del que ya poseemos. Por tanto, dar la razón al otro implica asumir, en el contexto del problema de si es posible o no la comprensión intercultural, que lo que el otro hace o dice, aunque nos parezca extraño o paradójico, puede modificar nuestros horizontes de comprensión en un sentido positivo, es decir, puede producir un cambio en nuestra comprensión que haga que ésta sea menos dogmática y más razonable, pues se trata precisamente de dar la razón al otro en señal de que se le permite expresarse y de que se admite la posibilidad de que lo que nos diga pueda ser valioso para nosotros y pueda producir un cambio en "los términos de nuestra autocomprensión"14. Lo que prima es que la razón hable por boca de los dos (del "otro" y del "nosotros", términos ambos intercambiables en función de quién sea el que vea al "otro" y se entienda a sí mismo como un "nosotros"), que la comprensión sea racional y no dogmática, y para ello es necesario conceder al otro la oportunidad de expresarse y de que nos trasmita algo diferente o contrapuesto a lo que ahora tenemos por verdadero. La ampliación de los horizontes es siempre un proceso que tiende a hacer que la comprensión sea lo menos etnocéntrica posible, es decir, a evitar que la comprensión sea presa de la tradición cultural.

\section{Presupuestos hermenéuticos relativos a la comprensión cultural y la interculturalidad. Los horizontes de comprensión y el encuentro intercultural}

\subsection{Fusión de horizontes}

\subsubsection{Fusionar implica modificar}

Gadamer introduce la expresión "fusión de horizontes" en el noveno capítulo de Verdad y método, que versa sobre la "historicidad de la comprensión". Se trata de una metáfora que Gadamer emplea para

\footnotetext{
14 En el fondo, esta actitud no es sino una la del sabio que propone Sócrates: no creer que lo que ya sabemos o simplemente lo que sabemos es inamovible o no puede ser sustituido o ampliado. Cf. PLATÓN. Teeteto, Biblioteca Nueva, Madrid, 2003.
} 
explicar su noción de comprensión. Pretende desactivar algunas acepciones de este concepto y activar otras. Se basa en distintos autores para fundamentar su concepción de la comprensión, aunque se distancia también de ellos, como ocurre con Dilthey y Schliermacher.

Según este último autor, toda interpretación es un dar sentido a lo que se interpreta. El estudio de esta dotación de sentido es uno de los objetivos principales de la hermenéutica textual ${ }^{5}$. Gadamer quiere llevar el problema de la interpretación más allá de la hermenéutica de los textos. Aunque toma como paradigma de hermenéutica a la hermenéutica bíblica de Schliermacher o a la hermenéutica de las ciencias humanas de Dilthey, pretende rebasar el planteamiento del problema que realizan estos autores y su respuesta misma al problema. Se propone renovar el problema de la comprensión. Se encuentra dentro de la tradición de pensamiento que inauguran aquellos dos pensadores -los cuales, a pesar de no ser los primeros en plantear el problema de la interpretación, establecieron el punto de partida de la hermenéutica moderna-, pero introducirá un cambio fundamental que revolucionará dicha tradición.

Por tanto, aunque se basa en Dilthey para estudiar el problema de la comprensión, Gadamer intentará superar su planteamiento, sobre todo porque considera que, a pesar de haberse separado del historicismo y de la epistemología cartesiana, sigue pensando el objeto de estudio de las ciencias humanas desde el marco de reflexión que proporciona dicha epistemología. La fundamentación que realiza de la objetividad del conocimiento de las ciencias humanas sigue siendo cartesiana ${ }^{16}$. Gadamer encuentra una falla fundamental en el planteamiento cartesiano del problema de la comprensión, y cree que

15 Entre los filósofos del pasado siglo más destacados que han cultivado esta clase de hermenéutica se encuentran P. Ricoeur (por su monumental obra, en tres volúmenes, Tiempo y relato) y J. Derrida (por sus tres importantes aportaciones realizadas en 1969: De la gramatología, La voz y el fenómeno y La escritura y la diferencia). Otros estudiosos de la hermenéutica de los textos desde el campo de la teoría de la literatura son $\mathrm{H}$. Eco y W. Iser.

16 GADAMER, Hans-Georg. Verdad y método, Sígueme, Salamanca, 1987, pág. 324. 
esta falla se encuentra también en Dilthey, lo cual genera una gran aporía en su pensamiento: tratar de desvincularse del cartesianismo epistemológico para pensar la naturaleza de las ciencias humanas y el método que éstas emplean sin dejar de concebir el conocimiento en términos de sujeto-objeto ${ }^{17}$.

Comprender en sentido gadameriano consiste en enlazar lo ya comprendido con lo que no se comprende todavía. Comprender es siempre comprender algo nuevo. Pero la novedad no se incorpora a un espacio vacío: hay siempre algo que acoge lo nuevo. Sin disponer ya de algo comprendido no podría tener lugar la comprensión. Lejos de ser un obstáculo para la comprensión, lo pre-comprendido es lo que hace posible lo que se comprende por vez primera. Los juicios que aportan conocimiento nuevo no serían posibles sin pre-juicios.

Tal y como hemos dicho, lo que se comprende por vez primera no es incorporado desde y a un vacío comprensor; hay siempre algo ya comprendido cuando se comprende. Pero hay que añadir que eso ya comprendido es rebasado por lo nuevo comprendido. Sin este rebasamiento no habría comprensión. El rebasamiento no es una eliminación de lo ya comprendido, sino una fusión con lo nuevo por comprender. En rigor, la fusión entre lo uno y lo otro es la comprensión. Cuando lo nuevo por comprender se asimila a lo ya comprendido tiene lugar la comprensión. Por eso Gadamer emplea la metáfora de la fusión: fusionar algo que ya se posee con algo que se espera poseer. Comprender algo implica siempre que ese algo todavía no se comprendía. Cuando se comprende se ha comprendido algo nuevo. Lo que es -ahora, en el presente- objeto de comprensión todavía no forma parte de lo comprendido. Y esto que está por comprender no puede ser comprendido si no se ha comprendido ya algo. La comprensión no puede tener lugar sin pre-supuestos. Hay siempre ya pre-supuestos y pre-juicios que actúan como horizontes de la comprensión. Y se comprende lo nuevo desde ellos: lo nuevo

17 Cf. Ibídem, cap. 11. Gadamer puso de manifiesto otras aporías en el pensamiento de Dilthey. Cf. GRONDIN. Introducción a Gadamer, ed. cit., pág. 112 y ss. 
comprendido no destruye esos horizontes, pues precisamente éstos han hecho posible que se haya incorporado eso nuevo. Si lo nuevo por comprender destruyera lo ya comprendido no podría haber comprensión. Porque lo que hace posible la comprensión es la modificación en lo ya comprendido. Sin esta modificación no puede tener lugar la comprensión. Al modificar lo ya comprendido acontece la comprensión (de algo nuevo) ${ }^{18}$.

Es insostenible, por tanto, la idea de que comprender implica eliminar lo ya comprendido para incorporar lo nuevo por comprender, porque si no permaneciera -aunque modificado, fusionado con lo nuevo- lo ya comprendido no podría incorporarse lo nuevo.

Cuando preguntamos a alguien: "¿Lo has comprendido?", presuponemos que lo que ha de comprender no es comprendido, y que la comprensión precisamente consiste en adquirir nueva comprensión. Este ejemplo nos muestra que comprender equivale a comprenderalgo-nuevo. La noción misma, por tanto, de comprensión lleva consigo la connotación de incorporar algo nuevo a nuestro comprender.

Veremos más adelante cómo Taylor toma esta noción gadameriana de comprensión para elaborar un argumento en contra del etnocentrismo. Según el etnocentrismo no es posible comprender desde dos marcos culturales de comprensión distintos ${ }^{19}$. Frente a ello, el filósofo canadiense defiende que la comprensión desde dos marcos culturales distintos sí es posible -y en particular la comprensión de uno de esos marcos desde el otro.

\footnotetext{
18 Hemos empleado desde el comienzo del trabajo el verbo "comprender" y el sustantivo "comprensión" como equivalentes de los términos alemanes "verstehen" y "Verstehen". Deliberadamente hemos evitado el término "entender" (empleado en algunas traducciones castellanas de las obras de Gadamer) y "entendimiento" porque el significado filosófico de ambos remite a la clase de concepción que Gadamer critica, propia de la epistemología moderna.

19 "Si no es en sus términos, ¿de qué modo podemos entenderlas [a las otras personas], como no sea en los nuestros? ¿Estamos inevitablemente condenados al etnocentrismo?", Taylor, "Comprensión y etnocentrismo", ed. cit., pág. 211.
} 


\subsubsection{El trasfondo pre-juicial y la modificación de los horizontes}

Comprender implica descubrir algo nuevo, diferente a lo ya comprendido, o incluso algo que entra en conflicto con lo ya comprendido. Se produce necesariamente un choque o una fractura entre lo que ya conocemos y el nuevo conocimiento cuando se produce la fusión de horizontes. Esta fractura no tiene por qué ser destructiva para la comprensión previa o ya adquirida. Es una fractura que tiene la posibilidad de regenerarse de manera muy rápida, y en esta regeneración, la comprensión logra romper los límites que antes tenía y hacerlos más amplios. Porque de lo que se trata en la comprensión es de ampliar los horizontes que siempre tiene. No hay comprensión sin horizontes, sin límites que marcan lo comprensible y el proceso mismo de comprensión. No hay posibilidad de comprender sin disponer de "pre-juicios".

Gadamer cree que el fundamento de la comprensión es algo distinto al autoesclarecimiento del cogito, el cogito que se da a sí mismo luz para ver. Gadamer cree que la luz con la que ve la conciencia es una luz que se encuentra fuera de la conciencia. Es una luz que le viene dada, una luz que no produce la conciencia misma. La conciencia puede operar porque existe esa luz que no procede de ella misma. Este modelo de comprensión que Gadamer propone se fundamenta en la idea de que los horizontes que puede ganar tal comprensión se fusionan o bien en una misma conciencia o bien en varias; cuando sucede en varias, se avanza en la comprensión intersubjetiva. Dos sujetos con horizontes de comprensión distintos pueden llegar a ponerse en la situación comprehensiva del otro, es decir, pueden comprender "en los términos de la autocomprensión del otro" ${ }^{20}$. El encuentro entre los dos sujetos que avanzan comprehensivamente en la misma dirección es posible porque ambos amplían horizontes al modo en que se produce la expansión de dos ondas que tienen emisores distintos. Los emisores se encuentran en lugares distintos pero las ondas que emiten llegan a entrecruzarse o solaparse (over- 
lap). Y en este entrecruzamiento tiene lugar una mutua asimilación de las ondas de cada uno de los emisores. Se da un intercambio mutuo que no anula ninguna de las dos ondas ni tampoco a los emisores que las emiten ${ }^{21}$. Con esta metáfora se ilustra la idea según la cual es el encuentro entre dos individuos distintos lo que permite la ampliación de los horizontes que cada uno posee. Gadamer emplea una expresión para nombrar a ese encuentro motivador de comprensión intersubjetiva, de un encuentro que permite el ensanchamiento de los horizontes de cada una de las partes, al cual hicimos alusión en la Introducción: "que el otro pueda tener razón" y que nosotros podamos no tenerla, es decir, que cada uno pueda otorgarse a sí mismo la posibilidad de no tener razón, la posibilidad de que sea el otro el que tiene la razón. Que el otro pueda "tener razón" significa en este contexto: que la cosmovisión (Weltanschauung) del otro, que a priori pueda resultarme errónea e incluso absurda, pueda llegar a ser parte de mis propios horizontes de comprensión.

Los horizontes de la conciencia no son interpuestos por la propia conciencia. Tales horizontes son dados a la conciencia; la conciencia no sería tal conciencia sin esos horizontes que se encuentran actuando "silenciosamente"22. Esos horizontes forman parte de la "historia efectual" de la conciencia, la cual se encuentra oculta para la propia conciencia cuando está activada o en funcionamiento. La conciencia es posible porque esa historia se ha forjado, porque los horizontes actúan cuando está siendo efectivamente conciencia. Pero la conciencia no puede hacerse consciente al mismo tiempo de esos horizontes que la hacen posible. El fundamento de esos horizontes no se construye mediante la propia conciencia; pues la conciencia es el edificio construido después de que hayan sido establecidos los pilares básicos en que se sostiene.

El encuentro entre un agnóstico, un cristiano y un musulmán, por ejemplo, puede ampliar los horizontes de todos ellos. Cada uno de

21 Ibídem, pág. 212.

22 GRONDIN. Introducción a Gadamer, ed. cit., pág. 146. 
ellos puede aprender algo de los otros dos. Y pueden ampliar sus horizontes sin dejar a un lado los suyos porque el comprender mismo, estructuralmente, opera como nos dice la metáfora de la fusión de horizontes: el comprender no necesita abandonar los horizontes previos para poder adquirir nuevos; el comprender opera más bien partiendo siempre de unos horizontes y adquiriendo nuevos mediante la fusión con esos que ya tiene. Por eso los tres individuos mencionados pueden llegar a ponerse en la situación comprehensiva del otro sin tener que abandonar su propio marco de comprensión, sus horizontes y sus identidades culturales o religiosas. Los tres pueden ampliar los horizontes de su comprensión sin tener la necesidad de suprimir el trasfondo pre-juicial del que disponen. Siempre se requiere tener un trasfondo pre-juicial para comprender. La comprensión no sería posible sin este trasfondo. Y avanzar en la comprensión intercultural significa aquí ampliar los horizontes que poseo sin abandonarlos en el proceso de ampliación.

Las tesis etnocentristas pueden ser criticadas desde la teoría de la comprensión de Gadamer. Dicha teoría explica la naturaleza de la comprensión intercultural: los horizontes se amplían, no se eliminan o se sustituyen, porque es imposible crear un vacío de horizontes. El único modo que tengo para comprender al otro es ampliar los horizontes con los que ya cuento. Es errónea la idea de que un marco de comprensión nuevo se adquiere gracias a la eliminación del que ya se posee. Esta eliminación puede ser parcial, pero nunca total, porque la comprensión opera como fusión, y no como supresión y renovación desde un punto de partida nuevo. Por eso Gadamer critica la teoría cartesiana de la conciencia, que cree que puede partir de un nuevo fundamento sin necesidad de estar sosteniéndose ya en fundamentos previos $^{23}$. Y por eso la teoría de Gadamer refuta las tesis etnocéntricas que defienden que la comprensión entre culturas es imposible porque o bien se comprende desde una cultura o bien se comprende desde otra, pero nunca desde dos o más a la vez.

23 La crítica de Gadamer a Descartes y a la noción de conciencia de la epistemología moderna se realiza en Verdad y método, ed. cit., cap. 9. 


\subsubsection{Auto-interpretación e identidad cultural}

El artículo de Taylor sobre "La interpretación y las ciencias del hombre" constituye un complemento de la reflexión de Gadamer sobre las ciencias del espíritu y el problema del método, que había retomado de Dilthey para reformularlo en el seno de la recuperación del problema de la comprensión. La hermenéutica era para Dilthey el "órganon de las ciencias del espíritu". Esto había vertebrado su investigación sobre la comprensión. Ante esta investigación reaccionará Heidegger con otra de corte puramente ontológico, que trata de averiguar la "preestructura de la comprensión". Dicha estructura arraiga en el "carácter de ser" de la existencia del Dasein (esto es, en el remontarse al estrato del ser al que la tradición metafísica había superpuesto la noción de ente). Gadamer dice no seguir completamente la línea heideggeriana, ya que lo que pretende realizar no es tanto una ontología de la comprensión, cuanto "hacer justicia a la historicidad de la comprensión"24. Es decir, su propósito es el de desvelar la historicidad de la comprensión, la cual no había sido considerada como tal por la "filosofía de la reflexión" 25 que le había precedido. Dilthey, a pesar de su propósito de acometer una crítica de la razón histórica siguiendo la idea de Giambatista Vico de que los hechos históricos son en primera instancia producciones humanas ${ }^{26}$, no había logrado desprenderse de lo que Gadamer llama el "concepto científico de verdad", que está estrechamente vinculado a la "conciencia metodológica" presente tanto en el neokantismo que había tratado de llevar al terreno de las ciencias del espíritu lo que Kant había realizado con las ciencias de la naturaleza, cuanto en el propio Dilthey. El historicismo, que se había caracterizado por ser la opción alternativa al neokantismo, le había proporcionado a Dilthey, no obstante, una perspectiva distinta con la que abordar el problema de la comprensión en las ciencias del espíritu. Por ello, Gadamer considera que el planteamiento del hermeneuta alemán puede servir como punto de partida de la rehabilitación de

24 Ibídem, pág. 331.

25 Es el término que emplea Hegel en su obra Glauben und Wissen para criticar la teoría del conocimiento de Kant. Gadamer incluirá bajo dicha denominación al propio Hegel.

26 Cf. GADAMER. Verdad y método, ed. cit., cap. 7. 
una concepción no metódica de la verdad y de una concepción de la comprensión alternativa a la que está presente en la filosofía de la reflexión.

Gran parte de los seres vivos disponen de mecanismos para interpretar el mundo. La respuesta a un estímulo exterior es, por ejemplo, una interpretación básica del mundo. La autointerpretación presupone no sólo la capacidad de interpretar el mundo, sino también la de dirigir la interpretación a uno mismo sin dejar de interpretar al mismo tiempo el mundo. La autointerpretación surge, en rigor, en el seno de la interpretación del mundo. Y la atribución de significado presupuesta en el proceso de autointerpretación también puede tener lugar en el momento mismo en el que ésta se produce. Nuevos significados pueden nacer en el proceso de autointerpretación, y de este modo también nuevos objetos y acciones pasan a formar parte de la identidad propia que antes estaba compuesta sólo por una cantidad limitada de significados. También en la autointerpretación nos relacionamos de modo distinto con los objetos del mundo ya interpretados y con los significados con que hemos dotado a objetos y acciones. En el proceso continuo de autointerpretación se producen modificaciones, de tal modo que lo que antes sentíamos como nuestro ahora es algo ajeno. La capacidad que tenemos para dotarnos de una identidad depende entonces también de lo ya dado en el mundo. Nunca hay una identidad que se construya sin elementos ya dados en el mundo. Está siempre compuesta por algo que toma del mundo y que reelabora o simplemente asimila tal y como lo encuentra. Por eso la formación de la identidad es un proceso nunca concluido, siempre abierto. La identidad puede rehacerse, reconstruirse, y siempre que esto ocurre vemos que hay involucrados nuevos significados. La incorporación de dichos significados nuevos, por tanto, puede hacer que la identidad se rehaga en su totalidad. Pero esta modificación se lleva a término con menor frecuencia que la modificación parcial.

Tiene gran importancia en el contexto de un discurso sobre la alteridad cultural conocer en qué medida es posible asimilar significados pertenecientes a un contexto cultural distinto al nuestro. Son 
significados, en este caso, ya dados en el mundo. No es el propio individuo el que debe dotar de significado; su función es más bien la de reconocer dicho significado y asimilarlo. La asimilación del nuevo significado ya dado puede producir, como hemos indicado, un cambio radical en la identidad del individuo: la debilitación de uno de los pilares básicos que sostienen el edificio puede hacer que éste se venga abajo. De modo que los valores y creencias que ahora desconocemos -valores y creencias que poseen ya un significado y que para asimilarlo sólo tenemos que reconocerlo- pueden pasar a formar parte de nuestra identidad y modificarla sustancialmente. El contacto con otra cultura puede hacer que el antropólogo cambie su visión del mundo y de sí mismo, comience a interpretarse de modo distinto a como lo hacía. Y ello porque los significados mediante los que se interpreta han cambiado. Vemos así, en el ejemplo de los valores propios de una cultura que un individuo comienza a hacer suyos, que el significado precede a la autointerpretación, que el significado o conjunto de significados es el material del que se nutre la identidad. El significado puede comenzar a ser asimilado en un momento determinado, y es entonces cuando comienza la construcción de la identidad mediante la autointerpretación. Ésta siempre es previa a la constitución de la identidad y es posterior a la atribución de significados.

No nos interesaba en este apartado tanto decantarnos por la tesis de que todos los significados están ya dados o bien se construyen siempre sin referencia al mundo, cuanto mostrar que su presencia es necesaria para la construcción de la identidad. Cuando analicemos Building the Future podremos percibir que el concepto de identidad cultural es un concepto filosófico presente en su propuesta sociopolítica.

\subsubsection{Encuentro intercultural y horizontes de comprensión}

El empleo que Taylor realiza de la metáfora de la fusión de horizontes sólo puede ser comprendido desde lo que Gadamer ha dicho sobre el mismo en Verdad y método. Hemos visto ya en qué consiste para el filósofo alemán dicha fusión. 
La hermenéutica de Taylor constituye una herramienta teórica fundamental para analizar algunos de los problemas en torno a los que se ha debatido en antropología filosófica.

Taylor habla de un "lenguaje de contraste perspicaz" que permita traducir dos prácticas culturales que se oponen ${ }^{27}$ sin que sea necesario que una suprima a la otra ${ }^{28}$. La idea gadameriana de la "fusión de horizontes" significa aquí que los individuos de dos culturas diferentes no necesariamente deben abandonar su horizonte cultural de comprensión para poder ponerse en el lugar del otro. Podemos comprender que el rito que lleva a cabo un miembro de una tribu invocando al dios de la lluvia es una práctica que tiene valor para dicha tribu y no por ello tener que abandonar mi propio marco de comprensión de esa práctica y la comprensión misma que tengo de ella.

Taylor señala que una vía para poder ponerse en el lugar del otro y comprender en sus propios términos las prácticas que él lleva a cabo sin tener que abandonar mi propio horizonte de comprensión consiste en ganar nuevos horizontes. Para ello, es necesario adoptar una actitud receptiva, abierta a lo que el otro pueda decirnos sobre nosotros mismos desde su punto de vista, abierta a aceptar que lo que pueda decir en los términos de su autocomprensión sea algo valioso para la comprensión que tenemos de nosotros mismos y de nuestras prácticas. Estar dispuestos a escuchar lo que el otro puede decirnos sobre

27 El matiz de que se opongan es fundamental, ya que es lo que impide que puedan ser asumidas a la vez. En esto, precisamente, se apoya el argumento relativista de que toda práctica cultural vale por igual.

28 Dicho lenguaje no pertenece a ninguno de los dos bandos. Es un lenguaje distinto del "lenguaje de la comprensión" del que cada frente dispone. Taylor define en los siguientes términos a este lenguaje de contrastes perspicaz: "Un lenguaje en el cual podamos formular ambos modos de vida en cuanto posibilidades alternativas, vinculadas a ciertas constantes de lo humano vigentes en uno y otro. Ha de tratarse de un lenguaje en el que las variaciones humanas posibles se plantearán de tal manera que tanto nuestra forma de vida como la suya puedan describirse transparentemente como alternativas en el marco de dichas variaciones. Ese lenguaje de contrastes podría mostrar que el lenguaje de la comprensión de la otra sociedad está distorsionado o es inadecuado en algunos aspectos, o emitir un juicio similar sobre el nuestro". TAYLOR. "Comprensión y etnocentrismo", ed. cit., pág. 212. 
nosotros mismos es una actitud imprescindible para que tenga lugar el diálogo intercultural. Generar un cambio en nosotros mismos que nos permita adoptar una perspectiva distinta a la que ya poseemos es un comienzo sin duda prometedor de lo que puede nacer en el diálogo. Quizá en este diálogo escuchemos al otro decir cosas sobre nosotros mismos que nos resulten incomprensibles e incluso inadmisibles. Sin embargo, debemos concederle la posibilidad de que diga algo valioso con respecto a nuestra autocomprensión.

El individuo que, formado en una cultura, se propone comprender otra, como sucede en el caso del antropólogo cultural, quien -como parte del trabajo de campo que implica su investigación- debe vivir durante un determinado periodo de tiempo con una sociedad muy distinta a la suya -de la que quiere explicar algunas prácticas, compararlas con las de otras culturas, estudiar el vínculo que existe entre unas y otras, etcétera-, tiene que insertarse en esa cultura comprehensivamente. Es decir, su comprensión tiene que adoptar los horizontes que constituyen a la que puede ser su "segunda cultura", a la cultura en la que se inserta.

La comprensión del antropólogo cultural se encuentra "ya siempre"29 bajo horizontes de comprensión. No puede tener comprensión sin horizontes. Puede que los horizontes que hacen posible su comprensión no sean fácilmente modificables o simplemente tiendan a evitar el encuentro con otros horizontes. Pero esto no imposibilitará que esos horizontes se abran a otros nuevos y que el antropólogo pueda llegar a comprender la otra cultura sin abandonar la suya propia, es decir, que pueda introducirse en la comprensión propia de los individuos de la otra cultura sin abandonar su propia comprensión y sus propios horizontes.

Los horizontes de los que se dispone cuando tiene lugar el encuentro no pueden ser sencillamente eliminados o sustituidos por otros, como mostramos más arriba ${ }^{30}$. Siempre queda abierta la posibilidad 
de recuperar antiguos horizontes después de un largo proceso en el cual se han fusionado éstos con otros nuevos. Los nuevos horizontes siempre pueden ser disueltos. Por ejemplo, cuando cesa el encuentro intercultural, es posible que el individuo que ha adquirido nuevos horizontes, que ha fusionado los horizontes que tenía con otros nuevos, comience a perder esos horizontes nuevos. No se trata de que el proceso de fusión de horizontes sea reversible, sino de que pueden latir con mayor fuerza los anteriores horizontes cuando cesa el encuentro. Si el encuentro intercultural cesa, es probable que los horizontes ganados, y la amplitud de la comprensión correspondiente, se debiliten; pero no desaparecerán complemente, porque en el proceso de fusión de horizontes han quedado enlazados los anteriores con los nuevos y ya no hay posibilidad de fracturar éstos sin fracturar también aquéllos. Los horizontes ampliados son horizontes fusionados, y en esa medida no es posible revertir el proceso de fusión ${ }^{31}$.

La idea de la hermenéutica gadameriana de una concesión de que "el otro pueda tener razón" es de radical importancia para la hermenéutica intercultural. En efecto, la apertura al otro, el estar abierto al diálogo y estar dispuesto a escuchar lo que el otro tiene que decir, es una disposición que la hermenéutica defiende.

La experiencia en sentido hermenéutico es aquella que nos abre a nuevos horizontes. Y precisamente esta experiencia es el modelo de

31 Con todo, persiste el problema (que quizá no es posible resolver completamente con la teoría hermenéutica de la comprensión) de si es posible comprender en los términos de la autocomprensión del otro sin abandonar los nuestros. No obstante, hemos comprobado que Taylor toma la noción de comprensión gadameriana para intentar rebatir la tesis etnocéntrica, o al menos para debilitarla y mostrar que, incluso en el caso de que no fuera posible evitar dejar a un lado nuestra comprensión cuando adoptamos los términos de la autocomprensión del otro, esto no la haría imposible que. Precisamente lo que se afirma con la metáfora de la fusión de horizontes es que la comprensión no es posible sino porque los dos horizontes (en este caso culturales, el mío y el del otro) se fusionan; es decir, que sin la interpenetración de ambos no habría comprensión. De modo que no se trata de que -tal y como los etnocentristas plantean el problema- para comprender debamos estar a un lado o a otro, en un marco de comprensión o en otro, sino que comprender es propiamente fusionar esos marcos de comprensión. 
apertura al otro porque es una experiencia con la que se logra ampliar y abrir horizontes que estaban cerrados o incorporar nuevos. Lo fundamental de la experiencia hermenéutica es que con ella ganamos nuevos horizontes. Y ganar horizontes significa haber superado los límites de nuestra propia tradición, lo cual implica a su vez haber estado dispuesto a superarlos. Esta disposición es la que alimenta la continua experiencia en sentido hermenéutico. La experimentación continua en sentido hermenéutico conduce a agudizar lo que Gadamer denomina "la vigilancia de nuestra propia conciencia" y a estar, en consecuencia, dispuestos a escuchar al otro para ampliar nuestros horizontes y no ser presa de nuestras propias limitaciones.

La cultura determina el lenguaje comunicativo y el modo en que con éste nos relacionamos con los sujetos con los que lo compartimos. Las experiencias son comprendidas de modo diferente en función del significado que tienen los términos del lenguaje. El lenguaje empleado para comprender experiencias varía en función de la cultura en que se ha forjado, y esto es quizá lo que da lugar a la disparidad de los significados de los términos de lenguajes distintos y de la comprensión misma de la experiencia que se realiza mediante ellos. Esto podría impedir la "comprensión intercultural": si no comprendemos al otro en sus propios términos, es decir, si no lo comprendemos del modo en que él mismo se comprende, sólo podemos entonces comprenderlo en los términos de nuestra autocomprensión. Con lo cual caeríamos en el etnocentrismo. Hemos visto ya cómo Gadamer y Taylor niegan que comprender al otro en sus propios términos requiera abandonar los nuestros. En la sección dedicada a analizar Building the Future comprobaremos cómo esta negación es un presupuesto fundamental del planteamiento de Taylor: no estamos condenados al etnocentrismo.

Hemos extraído de la concepción gadameriana de la comprensión algunas consecuencias relativas al problema de la interculturalidad y la comprensión intercultural. Hemos visto cómo Taylor aplica la hermenéutica filosófica de Gadamer a problemas relacionados con el encuentro intercultural. La concepción de la interculturalidad de Taylor está impregnada de una perspectiva hermenéutica. Como fundamen- 
to de su crítica al etnocentrismo, hay una teoría hermenéutica de la comprensión y encuentro interculturales. La concepción gadameriana de la fusión de horizontes sirve como fundamento de la defensa de la comprensión intercultural, una defensa que sirve a su vez como punto de partida de la promoción de una política intercultural que haga frente a los conflictos que surgen en sociedades multiculturales como Quebec.

\section{Multiculturalismo e Interculturalidad: El caso Quebec}

\subsection{Presentación del caso Quebec}

En la actualidad hay contextos en que no se promueve en modo alguno intentar llevar a cabo una fundamentación de la comprensión intercultural. En muchos casos, el recelo de fundamentación se debe simplemente a factores políticos o religiosos. La ideología dominante, asentada plenamente en un Estado o territorio particular, impide que exista un ámbito público en el que se debata sobre los intereses que conciernen a todos los ciudadanos. Se concibe con recelo todo pensamiento crítico que la cuestione y, si se permite, la reflexión sobre asuntos públicos está claramente guiada por esa ideología. Con ello se favorece que incluso en los ámbitos intelectuales no se defiendan las teorías que han mostrado que el etnocentrismo y otras clases de concepciones no aperturistas son débiles enemigos y que pueden ser abatidos sin grandes dificultades.

Hay otros casos, aunque en número reducido, en que existe una voluntad expresa, por parte del gobierno político y de los ciudadanos, de encontrar "lo que nos une", de mostrar que existen vínculos que pueden más que lo que nos diferencia. Recientemente esta voluntad se ha expresado en Canadá, y en particular en la provincia de Quebec, donde el multiculturalismo es un factor social decisivo desde hace varias décadas.

El sentimiento nacionalista entre los ciudadanos francófonos quebeque ses se ha reforzado en los últimos años, debido en parte a que han creído que su cultura y su lengua han sido atacadas desde varios 
frentes. Lejos de haber contribuido a reducir dicho sentimiento, la llegada de múltiples etnias y las modificaciones realizadas en materia de políticas sociales -que han favorecido a los nuevos inquilinos- ha hecho que los quebequenses autóctonos hayan interpretado todo ello como una opresión hacia su identidad. Y esto último ha causado que se acreciente la preocupación por el destino que le espera a dicha identidad y se hayan alzado contra el propio gobierno.

Ante las manifestaciones de los ciudadanos que reclaman una mayor atención a la preservación de su cultura, el gobierno ha promovido que se realicen estudios académicos que puedan arrojar luz sobre este problema y que provean al propio gobierno de un plan de actuación ${ }^{32}$. El gobierno partía de la convicción-que todavía debía ser confirmada a través de los estudios mencionados- de que era necesario reforzar la cultura autóctona sin llegar a impedir la integración de otras culturas.

Jean Charest, alcalde ("Premier") de Quebec, anunció a comienzos de febrero de 2007 la constitución de la "Consultation Commission on Accommodation Practices Related to Cultural Differences", en respuesta a la petición de la ciudadanía quebequense que no estaba de acuerdo con las "prácticas de armonización" de las distintas etnias que el gobierno había llevado a cabo en la provincia canadiense. Charest aducía como justificación de tal constitución el hecho de que existiera, por un lado, un descontento público relativo a dichas políticas de armonización de la convivencia de los grupos sociales con procedencias culturales distintas $y$, por otro lado, resultados negativos derivados de la experiencia que los ciudadanos quebequenses autóctonos han tenido del acrecentamiento del reconocimiento de otras culturas en su tierra natal.

32 En una conferencia impartida en la Universitat de València el pasado 3 de febrero, el sociólogo Gérard Bouchard expuso cómo se puede extender a las sociedades multiculturales europeas este plan de cohesión social desarrollado en Quebec después de la publicación de los resultados de la investigación llevada a cabo por la comisión Bouchard-Taylor. 
Entre los objetivos con que dicha Commission se proponía cumplir se encuentra el de solucionar ambas situaciones, como vemos reflejado en el siguiente listado:

1) Evaluar la cantidad de acciones sociales existentes en Quebec que promueven el acuerdo.

2) Analizar el estado actual de la "experiencia de otras sociedades" que tienen los ciudadanos de Quebec.

3) Llevar a cabo una extensa consulta a los ciudadanos.

4) Formular recomendaciones al gobierno.

Es menester que existan determinados agrupamientos o asociaciones que tengan exclusivamente como objetivo -explícito o implícito- la cohesión entre ciudadanos que no comparten necesariamente las mismas creencias religiosas o que dispongan de marcos diferentes de comprensión que les hacen atribuir un significado, a algunas actividades o símbolos, distinto del que le atribuyen otros. Por ejemplo, el crucifijo no significa lo mismo para un musulmán, para un ciudadano que no se adscribe a ninguna religión, para un cristiano totalmente integrado en la cultura democrático-liberal o para un cristiano que forma parte de una congregación eclesiástica. La atribución de significados a ese símbolo o simplemente el hecho de considerarlo un símbolo, depende siempre del marco de comprensión en el que los individuos se encuentran. Y ese marco de comprensión está directamente influido por la formación social que los individuos reciben. Es en lo social donde el marco de comprensión arraiga y donde nacen los significados que cada individuo asume como propios y proyecta en actividades o materiales, a las que puede entender como actividades sacras o símbolos sacros, o, por el contrario, como actividades irrelevantes y materiales que no representan nada en absoluto. La atribución de significados a prácticas y materiales depende también de la historia de la sociedad en que se origina y desarrolla una religión, pues es allí donde también se origina y se desarrolla el significado que se le atribuye a dichas prácticas y materiales. El caso del culto propio de una religión nos permite apreciar con claridad esto. El culto y rito judíos resultan incomprensibles a quien desconoce la historia de esta religión. De tal modo que la comprensión de estos cultos y ritos 
religiosos depende siempre del conocimiento previo de la historia y de los textos que las religiones tienen por sagrados. Y ese conocimiento llega a los individuos a través de la formación, la cual no puede tener lugar sino en el seno de una sociedad. Esta formación es específica, es decir, es una formación pensada como parte de la integración del individuo en un grupo religioso. Pero también el individuo tiene acceso a fuentes de formación no religiosa. De tal modo que, frente a la especificidad de la formación para la comprensión del culto y ritos de la religión a la que se adscribe, se encuentra otra formación de la que también requiere en tanto que ciudadano de una sociedad democrático-liberal. En efecto, todo ciudadano perteneciente a este tipo de sociedades necesita, aun si pertenece a un credo religioso concreto, una formación en ciudadanía. Sin duda tenemos un ejemplo de esto en los actuales programas educativos sobre educación para la ciudadanía, que pretende ser una materia neutral con respecto a las distintas formaciones religiosas ante las que se propone como alternativa ${ }^{33}$.

De esta manera, todo ciudadano debe tener una formación que le permita ser parte integrante de la sociedad en la que convive, aun si esta sociedad está formada por individuos que no conocen o rechazan las creencias religiosas que tal ciudadano tiene. Por ello, el fortalecimiento del credo social del que todo individuo de una democracia-liberal participa es una labor fundamental del gobierno político. Así se expone en el Informe Bouchard-Taylor. Sin duda sin esta promoción de una formación para la convivencia entre ciudadanos de etnias y religiones distintas parece difícil que pueda haber una verdadera armonización e integración de tales ciudadanos en una misma sociedad. Si se establece por principio que la convivencia entre distintas culturas es posible e incluso necesaria -principio intercultural fundamental que se propone para la sociedad quebequense-, entonces el fortalecimiento del credo social compartido es una de las tareas fundamentales que el gobierno político debe acometer.

33 Para un debate sobre el problema de la "neutralidad" de las materias alternativas a la religión, cf. MACLURE, J. y TAYLOR, Ch. Laicidad y libertad de conciencia, Alianza, Madrid, 2011. 
Los ciudadanos quebequenses deben compartir asimismo un credo político. Provengan de donde provengan, tengan mayor o menor conocimiento de la historia política de Canadá y la legitimidad de un gobierno democrático, todos ellos han de contribuir a forjar su nación, es decir, todos deben luchar en una misma dirección, por una misma causa, expresada en su actividad política, que no consiste sólo en adscribirse a un partido político e introducir en una urna el día de las elecciones una papeleta que haga constar su decisión, sino también en llevar a cabo otro tipo de actividades que afecten directamente a la política de su país.

La consulta a los ciudadanos realizada por los investigadores de la Comisión Bouchard-Taylor puede tener efectos positivos, pero, a nuestro juicio, tiene mayoritariamente efectos negativos. Primero, porque los ciudadanos que participan en un referéndum sin consecuencias políticas o jurídicas inmediatas no otorgan la misma importancia a la información que van a proporcionar a través de su voto o de su palabra que a la que se demanda de ellos el día de las elecciones provinciales o nacionales. De modo que la información obtenida por medio de consultas masivas frecuentemente no refleja realmente la opinión pública. Segundo, porque aunque la información fuera verídica, sólo habría sido obtenida de una parte de la población (éste es, por lo demás, uno de los principales problemas que presenta el modelo de democracia representativa). Quienes no participen en la consulta pueden tener una opinión que cambie drásticamente la información obtenida y las conclusiones extraídas. Esto afecta directamente al cuarto objetivo de la Comisión expuesto más arriba. No se pueden formular recomendaciones al gobierno con respecto a cómo debe actuar para con los ciudadanos sin tener en cuenta a todos. La solución sería convocar no ya un referéndum voluntario, sino un referéndum al que los ciudadanos están llamados a participar de forma obligatoria ${ }^{34}$. No se trata sino de

\footnotetext{
34 No obstante, siempre cabe la posibilidad de que los ciudadanos no manifiesten su verdadera opinión por ser obligados a participar en algo en lo que no creen o detestan. Pero creemos que al menos se lograría incrementar la participación de aquellos ciudadanos que sí apoyan la democracia pero que no se involucran en ella por una clase de razones distinta a la que tienen quienes defienden el anarquismo u otra forma de gobernar políticamente diferente de la democracia representativa.
} 
un ejercicio plenamente democrático, pues lo que se persigue con ello es contar realmente con la voluntad del pueblo. Si no se tiene en cuenta la opinión de todos y cada uno de los ciudadanos (es decir, de quienes cumplen con la condición de ciudadanos), no se actuará de manera legítima cuando se tomen decisiones en cuestiones que afectan a todo el pueblo quebequense. Por supuesto, es sólo una propuesta, que implicaría radicalizar los mecanismos democráticos de participación e implicación de los ciudadanos en la política. Del mismo modo que los ciudadanos tienen la obligación de pagar impuestos destinados a financiar actividades colectivas o individuales auspiciadas por el Estado cuando son necesarias (sanidad pública, puestos públicos de trabajo, ejército nacional, etcétera), deberían tener también la obligación (y en este caso no hay ninguna pérdida económica) de pronunciarse ante el pueblo y el gobierno y hacer constar cuál es su voluntad con respecto a la política (incluso si su voluntad es que no exista política alguna o que se sustituya la democracia por otro régimen político). Esto es necesario sobre todo cuando, como en Quebec, hay confusión incluso entre las clases políticas sobre la percepción pública del fenómeno del multiculturalismo. Los distintos casos que Bouchard y Taylor exponen sobre las falsas percepciones que existen de conflictos multiculturales dan cuenta de la necesidad de disponer del juicio de todo el público para actuar correctamente en materia de política multicultural.

En consonancia con el espíritu intercultural que caracteriza a Canadá en su totalidad, Quebec ha tratado de no dar la espalda a las distintas culturas que de hecho conviven en el amplio territorio que ocupa la provincia. Bouchard y Talyor tratan de mostrar, a raíz de minuciosos estudios sociológicos y políticos, por qué los ciudadanos de Quebec, provengan de donde provengan, deben mantener estrechos lazos políticos y sociales. Ambos autores han abogado por establecer políticas interculturales que no impliquen medidas judiciales. Han propuesto reformar la normatividad social que de hecho se encontraba ya vigente.

Este Informe pretende trasmitir a un público amplio las razones por las cuales los ciudadanos no han de temer a estrechar vínculos entre 
sí y a aceptar que pueden convivir armoniosamente si comparten una serie de normas sociales que no se basan en ideas religiosas o de una cultura en particular. Son normas establecidas de acuerdo con un modelo de ciudadanía multicultural amplio, que tiene sus bases en el liberalismo en el sentido en que Taylor lo concibe ${ }^{35}$.

A la propuesta de Bouchard-Taylor, que se expone fundamentalmente en la sección cuarta del Informe abreviado ${ }^{36}$, subyace la hermenéutica de la comprensión intercultural que hemos visto en el apartado anterior. En efecto, en la base de la teoría social desarrollada en este Informe encontramos la teoría hermenéutica de la fusión de horizontes reformulada por Taylor en su ensayo "Comprensión y etnocentrismo".

Los autores del Informe pretenden mostrar que los múltiples conflictos que han tenido lugar en los últimos quince años en Quebec no han puesto en cuestión las bases interculturales presentes en las normas sociales de Quebec. Los casos en que se han puesto en cuestión las prácticas de armonización de las distintas culturas y religiones que conviven en Quebec son muy reducidos. Los autores intentan mostrarlo de distintos modos.

Uno de los casos más llamativos es el de un grupo de musulmanes que realizan el culto en un establecimiento público porque no disponen de un lugar privado. La supuesta ruptura de la armonización consistiría en que este grupo de musulmanes no ha respetado a los demás ciudadanos que desconocen el Islam o que no quieren tener ningún contacto con él y en que, además, han tenido que desplazar a las personas que se encontraban en ese lugar para poder llevar a cabo el culto. La percepción general de este hecho es que este grupo de musulmanes está poniendo en cuestión el orden público establecido. Los autores intentan mostrar

35 Véase su análisis del caso Quebec en El multiculturalismo y la política del reconocimiento, en el que expone los problemas concernientes a la convivencia desde el punto de vista del liberalismo político.

36 Cf. BOUCHARD, G. y TAYLOR, Ch. Building the Future. Abridged Report, ed. cit., págs. 35 y ss. 
que, en caso de que sea así, sólo hay que hacer pequeñas modificaciones en la regulación de las prácticas religiosas en público. No hay detrás de este caso un problema grave de malentendidos entre culturas. No hay razones de peso que nos permitan hablar de un conflicto entre culturas. Los pequeños conflictos tienen solución.

La justificación de la defensa de Bouchard y Taylor de una ciudadanía intercultural se encuentra en los argumentos que demuestran que la comprensión intercultural es posible.

Puesto que la comprensión intercultural es realmente posible, ¿por qué rechazar la convivencia entre culturas y no intentar solucionar los pequeños problemas que puedan surgir en dicha convivencia?

\subsection{El malestar identitario en Quebec}

En la identidad cultural se encuentran conglomerados los ideales del pasado, los ideales que ahora forman parte de la tradición. Dichos ideales rebasan la finitud del tiempo que pertenece esencialmente a la naturaleza humana. A pesar de no ser eternos -pues al tiempo que se deja de considerar significativa a la tradición, dichos ideales comienzan a ser sustituidos parcial o totalmente por otros-, se mantienen intactos durante más tiempo que los individuos que los defienden.

Tales ideales pasan a formar parte de la identidad de los individuos que los acogen. La identidad cultural es en este sentido un cúmulo de características sociales y políticas que constituyen el núcleo de una cultura, la cual es a su vez asumida en cada individuo como propia ${ }^{37}$. La identidad cultural es algo que se comparte en un grupo determinado de individuos. No es nunca algo exclusivo de un individuo. Es una identidad colectiva. En este sentido cabe repensar cómo los ciudadanos quebequenses se conciben a sí mismos culturalmente -cómo cada grupo étnico, político, social, económico, etcétera, se concibe a sí mismo

37 Cf. TRÍAS, E. "Identidad cultural", en Conill, J. Glosario para una sociedad intercultural, Bancaja, Valencia, 2002, pág. 192. 
en función de sus diferencias con otro ${ }^{38}-$, cómo entienden la cultura en la que viven, los ideales a los que se adscriben, los símbolos a los que otorgan significado. Una característica importante de la cultura quebequensa es la laicidad; esto es, la desvinculación de los ideales que defiende cualquier religión. Los ideales culturales de Quebec son seculares. En efecto, buena parte de los ideales culturales tienen que ver directamente con la religión. En el caso de Quebec, lo que se expresa en dichos ideales culturales es una desvinculación generalizada del culto a una determinada religión. La libertad de religión y expresión forma parte de la sociedad en la que políticamente no se reconoce a un credo religioso como el oficial del Estado.

En los últimos años los musulmanes de Quebec han sido acusados de haber repercutido de manera negativa en la vida pública canadiense. La imagen que se tiene de los musulmanes en la actualidad ha cambiado significativamente de la que se tenía antes de los atentados terroristas del 11 de septiembre de 2001 en EEUU ${ }^{39}$. Los actos terroristas realizados por miembros de clanes musulmanes han contribuido a generar una imagen pública negativa de los musulmanes en general, lo cual ha hecho que, al mismo tiempo, en el caso de Quebec, los ciudadanos tiendan a reafirmar su identidad y a entender que los miembros de la religión musulmana contribuyen a destruir su propia cultura. Los quebequenses que han sentido cómo su cultura autóctona ha desaparecido a medida que el multiculturalismo se ha acrecentado, han introducido en la opinión pública una imagen negativa de las "otras" culturas. Se considera que ésta no es sino la causa del malestar de la identidad cultural de los quebequenses francófonos. A pesar de que no podemos pasar por alto el hecho de que también estos ciudadanos de ascendencia franco-canadiense están formados en una cultura importada desde Europa a América, lo cierto es que ha existido una tradición cultural

38 La identidad de un grupo nace siempre en la confrontación y diferenciación con otro u otros., como señalamos más arriba.

39 BOUCHARD, G. y TAYLOR, Ch. Construir el futuro. El tiempo de la reconciliación, Observatorio vasco de inmigración, Gipuzkoa, 2010, pág. 67. 
durante más de dos siglos que ha estado alimentada por la religión y que en la actualidad ha perdido parte de su predominancia debido al multiculturalismo, el cual ha favorecido la promoción de políticas que tratan a todas las religiones por igual.

El rechazo de las prácticas de armonización de las distintas religiones y etnias que coexisten en Quebec ha sido realizado sobre todo por parte de aquellos ciudadanos franco-canadienses que consideran que perjudican irreversiblemente la identidad cultural original de la que ellos gozaban antes de la "Revolución Tranquila", a través de la cual se ha instituido el laicismo y la igualdad de derechos entre hombres y mujeres. Como dicen en el Informe Bouchard y Taylor, la pequeña "crisis" en que han entrado dichas prácticas se debe precisamente al hecho de que hayan "abierto viejas heridas" 40 en los ciudadanos quebequenses. En el Informe abogan por satisfacer tanto a las peticiones de estos últimos como a los del resto de colectivos que poseen una identidad cultural propia:

"La identidad heredada del pasado franco-canadiense es perfectamente legítima, pero no puede ocupar ella sola el espacio identitario quebequense. Debe articularse con las otras identidades presentes, según el espíritu de la interculturalidad" ${ }^{41}$.

Frente a la desesperanza en la forja de una identidad y un futuro común, los autores del Informe proponen construir una "identidad común", basada en el laicismo y el reconocimiento de la igualdad de todos los hombres y mujeres. Dicha construcción se cifra además en factores como: 1) la posesión de una lengua común; 2) la promoción desde las instituciones educativas públicas de la formación en ciudadanía intercultural; 3) y la creación de una memoria nacional ${ }^{42}$.

$40 \quad$ Ibídem, pág. 68.

41 ídem.

42 Ibídem, pág. 75. 
Otro de los problemas políticos relevantes que acucian en la actualidad a los políticos canadienses es el de si deben responder afirmativamente o no a la demanda de gran parte de la población quebequense de libertad para independizarse como nación. Factores como la posesión del francés como primera lengua y el bajo porcentaje de angloparlantes -a diferencia de lo que sucede en el resto de provincias canadienses- han contribuido a reforzar el sentimiento nacionalista y patriótico entre los ciudadanos de Quebec. Como ocurre en muchos otros Estados de los continentes americano y europeo, existe una escisión interna con respecto a los ideales que políticamente deben reconocerse.

Sirve de ejemplo a este efecto el caso de España y Cataluña. El gobierno autonómico de Cataluña ha propuesto realizar un referéndum para lograr legítimamente la independencia estatal. Aunque el gobierno español ha propuesto abolir algunas leyes que permiten realizar consultas de esta clase, el gobierno catalán se propone transformar las elecciones autonómicas en un referéndum a fin de mostrar que son mayoría los votantes que prefieren la independencia. El presidente de la Generalitat de Catalunya cree firmemente que puesto que su partido político ha obtenido la mayoría en las pasadas elecciones y puesto que su partido reivindica la independencia, entonces, si se transforman en referéndum las próximas elecciones, los votantes elegirán la independencia. Sin duda aquí hay involucrados no sólo problemas políticos, sino también lingüísticos e incluso económicos. España se encuentra en la actualidad inmersa en un debate político similar al que han mantenido Canadá con Quebec. En Quebec también existe un fuerte sentimiento independentista, que ve a Canadá como opresora para la identidad del pueblo quebequense. En efecto, existen también problemas identitarios que han tenido lugar debido en parte a que Quebec sea una población francófona y que se entienda a sí misma como diferente de las demás provincias canadienses. La identidad se genera solamente con la confrontación de lo diferente. Sin algo de lo que diferenciarse la identidad no sería posible. El "malestar identitario", como lo denominan Bouchard y Taylor, ha sido originado por causas como ésta. Y ello ha dado lugar al refuerzo del sentimiento nacionalista de algunos partidos políticos 
y de los ciudadanos que se adscriben a ellos, lo cual ha revertido a su vez en el aumento de la percepción del multiculturalismo como un grave inconveniente e incluso enemigo del mantenimiento de la cultura autóctona quebequense. El multilingüismo es, por tanto, también uno de los factores decisivos que han motivado el rechazo del multiculturalismo. Porque multiculturalismo suele ser sinónimo del multilingüismo. Y si existen múltiples lenguas conviviendo, sin que unas tengan preferencias sobre otras, la o las lenguas autóctonas adquieren el mismo estatus que las demás, lo cual contribuye a hacer que quienes tienen como lengua materna a una lengua autóctona vean como se deteriora la prevalencia de su cultura. En efecto, el decrecimiento del predominio de una lengua causa el decrecimiento del predominio de la cultura a la que está ligada y viceversa. Con lo cual los ciudadanos quebequenses francófonos y otros pueblos que tienen su propia lengua ven como una amenaza para el mantenimiento de su propia cultura el hecho de que su lengua materna no sea promovida con preferencia con respecto a las demás.

Como vemos, los problemas políticos provocados por la irrupción del multiculturalismo son múltiples y es difícil establecer una respuesta que satisfaga a los grupos que realizan al gobierno peticiones que en ocasiones contradicen las peticiones de otros grupos. El Informe de Bouchard y Taylor pretende, sin embargo, asumir la multiplicidad que está presente de hecho en la sociedad quebequense y elaborar una respuesta que satisfaga a la mayoría de los ciudadanos.

La expresión pública de creencias, valores o ideales morales o religiosos a través de símbolos o discursos no está permitida en la actualidad en Canadá. Esta "voluntad general" de no permitir expresar nada que perturbe el orden público tiene, repetimos, su fundamento en la teoría política liberal que subyace a la constitución de Canadá de 1982. Frente a ello los autores del Informe apuestan por promover el "permiso a la expresión pública de las diferencias" ${ }^{43}$.

43 BOUCHARD y TAYLOR. Construir el futuro. El tiempo de la reconciliación, ed. cit., pág. 60. 


\subsection{Reformulación de las prácticas de armonización y propuesta de normas colectivas en el Informe Bouchard- Taylor}

Algunos de los antecedentes más significativos de intentos de establecer prácticas de armonización, surgidas por iniciativas políticas con el claro objetivo de producir cambios en la percepción que los ciudadanos tienen de "los otros" y reconducirla en aquellos casos en que esa percepción impide una correcta convivencia de grupos de distinta procedencia cultural y, en consecuencia, de contribuir a forjar un concepto o modelo de ciudadanía intercultural, son las ya célebres normativas que impiden vestir o llevar en público símbolos religiosos, símbolos que no constituyen, para quien practica la religión en cuestión, solamente una representación de sus creencias: la religión obliga también a llevarlas en público, debido a que se considera que el no llevarla significa unívocamente no estar de acuerdo y no actuar en consonancia con esas creencias. En caso de no vestir, por ejemplo, el "Muslim headscarf" o el "kirpan", se estaría impidiendo a la religión mostrarse en público. Esto nos hacer ver la necesidad de establecer límites al derecho de libertad de expresión y religión que aparece recogido en la primera enmienda a la Constitución de los Estados Unidos, que sin duda ha influido en la canadiense. El caso de "Muslim headscarf" es significativo porque para quien profesa la religión que obliga a llevarlo no tiene alternativa: si el Derecho público establece la prohibición de portar símbolos religiosos en público, estos no pueden en ningún caso -queda bajo su responsabilidad hacerlo o no- mostrar dichos símbolos, a menos que no les importe ser expulsados de los lugares públicos o ser sancionados continuamente con las penas correspondientes. La posibilidad de prohibir vestir cualquier tipo de atuendo que tenga significado religioso fue contemplada por el Parlamento Superior canadiense a comienzos del siglo XXI, después de los aterradores sucesos que tuvieron lugar en Estados Unidos el 11 de septiembre de 2001.

Un factor que sin duda ha contribuido a generar conflictos sociales relacionados con la vestimenta que simboliza algún credo religioso es el hecho de que sean precisamente grupos religiosos no autóc- 
tonos ${ }^{44}$ en Quebec los que más símbolos llamativos llevan consigo. Hay otros factores como la realización en público de los cultos y ritos propios de cada religión que también influyen sin duda en la creación de una imagen pública negativa de la religión, como ya vimos.

Los ciudadanos que no profesan ninguna religión se sienten ofendidos al ver cómo otros que sí lo hacen la expresan en público. En una sociedad secular, en la que ninguna religión mantiene un vínculo político ni jurídico con el Estado -pues el documento oficial por el que éste guía su actuación es una constitución en la que se establece con claridad la aconfensionalidad-, no puede permitirse el uso de símbolos religiosos en público.

Aunque Bouchard y Taylor conceden gran importancia a la libertad de los ciudadanos a la hora de elegir su propio destino social -el conflicto o la convivencia pacífica y cordial- así como al sentimiento de responsabilidad que debe caracterizar a ese ejercicio de la libertad, no obstante también considera importantes las normas sociales colectivas. Aunque estas normas no tengan carácter jurídico o legislativo, sin embargo pretenden tener un efecto inmediato, con el fin de garantizar que exista un cierto orden en las relaciones que mantienen los ciudadanos en la esfera pública. El sistema normativo ideado tiene que elaborarse siempre teniendo como horizonte su aplicación, es decir, tiene que elaborarse contemplándose cómo va a ser aplicado. Debe ser un sistema pensado para la praxis. No basta con que refleje ideales democráticos, con que en él se hable de derechos que deben ser garantizados, con que goce de un contenido a la altura de lo que un Estado liberal puede ofrecer; debe también recoger el modo en que será aplicado y qué fases va a seguir dicha aplicación. Debe planificarse, por tanto, en la propia fundación de los documentos de carácter oficial destinados a regular las relaciones sociales de los ciudadanos el modo en que van a ser aplicadas las normas. No se trata de predecir

44 Por "religiones autóctonas de Quebec" entendemos aquellas que fueron instituidas a comienzos del siglo XVII, no las aborígenes existentes con anterioridad a la conquista del territorio llevada a cabo por Gran Bretaña y Francia. 
todos los casos particulares a los que se aplicarán las normas, sino más bien de asumir que no se puede presuponer que la aplicación tiene lugar de suyo cuando se elabora un código deontológico coherente y autosuficiente. En el propio código normativo deben quedar recogidas las distintas formas en que debe ser aplicado. Si no se contempla dentro del propio código el modo en que debe ser aplicado, no existen garantías de que vaya a ser efectivo. Al igual que la estadounidense, la sociedad canadiense $-y$, en particular, la quebequense- se enmarca en la tradición política democrático-liberal.

Las normas sociales a las que hemos hecho alusión se caracterizan por constituir los "fundamentos de la cultura pública común" ${ }^{45}$ de Quebec. Estas normas que tienen vigencia social pero no legal, esto es, las que están actuando de hecho en la realidad social a pesar de no aparecer recogidas en códigos jurídicos. Son de gran importancia en tanto constituyen, para los autores, el marco de referencia de las prácticas de armonización. Esto es, dichas prácticas, a diferencia de lo que opinan algunos de los ciudadanos en las encuestas llevadas a cabo durante la investigación, sí disponen de un marco de referencia en el que basarse. Aunque dicho marco no está compuesto de "directrices jurídicas", no por ello está falto de otras directrices. Posee directrices sociales. Lo único que habría que hacer para satisfacer las peticiones de los ciudadanos que opinan que las prácticas de armonización no han hecho sino incrementar los conflictos entre aquellas partes que pretendían cohesionar y que opinan también que no hay un marco cívico común en el que fundamentar dichas prácticas, sería reformular o precisar cómo deben llevarse a cabo y los objetivos que se persiguen con ella a partir del diseño de un nuevo modelo de integración que

\footnotetext{
45 "La sociedad quebequense -señalan los autores- ha adoptado en los últimos años un conjunto de normas y reglas que fortalecen a su 'cultura pública común'". Ibídem, ed. cit., pág. 34. Esta afirmación está extraída del siguiente pasaje: "One of the key sources of anxiety mentioned during our consultations concerns the putative absence of guidelines to handle adjustment requests. Aside from the legal guidelines indicated (...), Quebec society has nonetheless adopted over the years an array of norms and guidelines that underpin its 'common public culture'. It is thus wrong to believe that there are no guidelines governing harmonization practices [in Quebec society]".
} 
tome como referencia principal los derechos que debe amparar una democracia liberal multicultural así como el principio de no defender ni permitir que ninguna religión se vincule al poder político.

Para elaborar dichas normas es menester saber primero cuáles cumplen con las condiciones necesarias y suficientes para poder ser denominadas normas "sociales". Toda norma requiere una fundamentación, es decir, una justificación de su contenido en tanto que norma. A quien se le impone un mandato puede preguntarse por el sentido de dicha imposición: por qué se impone ese mandato y no otro. La fundamentación de dicho mandato o norma actúa como respuesta al porqué de que haya que cumplir con esa norma y no con otra.

Los autores entienden que la formulación y establecimiento de estas normas sociales en códigos también sociales son parte de lo que debe realizarse para lograr la pretendida reconciliación que enuncian en el título de la obra (A Time of Reconciliation).

\section{Conclusiones}

Al igual que los horizontes culturales, los horizontes lingüísticos pueden quebrantarse; aunque establecen límites del pensamiento, pueden ser modulados y ampliados.

Los horizontes nos permiten ver, siempre a condición de limitar la visión (es decir, de dejarnos ver unas cosas y no otras). Sin embargo, esa limitación no es sino la condición de posibilidad de la visión, porque ver es siempre ver algo determinado y no el todo; no obstante, el campo de visión puede ampliarse, porque los horizontes pueden ser modificados: la visión puede ser más amplia, pero nunca lo suficiente como para eliminar esos límites. La ampliación de los horizontes sirve además como elemento regulativo de la visión que se tiene ya bajo esos horizontes. Siempre es posible ver más allá de lo que se ve, y por ello existirá siempre un más allá de la visión que se tiene. Los horizontes mismos demandan su propia ampliación; su configuración actual ha sido fruto también de una ampliación. De tal modo que los horizontes poseen una naturaleza dinámica y no estática. Por ello, habrá siempre 
un más allá de los horizontes que espera ser descubierto, lo cual nos permite albergar la esperanza de que la comprensión no es nunca un fenómeno claudicado. La comprensión tiene límites, pero estos límites son dinámicos y flexibles. De ahí que la comprensión siempre tienda a rebasarse a sí misma.

Como hemos comprobado, comprender es siempre comprender algo nuevo. Y aquí está implícita la posibilidad de que dos horizontes culturales muy distintos se fusionen. La comprensión intercultural es, en consecuencia, un ideal completamente alcanzable. La ruptura de los horizontes establecidos que es necesaria para que tenga lugar la comprensión intercultural es algo inherente y propio de la naturaleza de esos horizontes. Se fracturan como parte de su remodelaje. Sin este remodelaje no serían propiamente horizontes.

Desde ellos alcanzamos a ver, pero al mismo tiempo nos limitan la visión, como hemos demostrado. Y esto quiere decir que no hay visión posible si no hay horizontes. La visión cambia en función de los horizontes de que se disponga. Cuando los horizontes se modifican, la visión también lo hace. Y puesto que es algo natural a los horizontes esa modificación, el cambio en la visión correspondiente es inevitable. De tal modo que para poder aproximar dos visiones muy distintas hemos de dirigir a los horizontes en el proceso de modificación que siempre y continuamente llevan a cabo. Hemos de dirigirlos el uno hacia el otro. Únicamente cuando los dirigimos adecuadamente puede producirse la fusión entre ellos. De tal modo que dicha fusión depende de la actitud y los propósitos de los propios individuos.

Gadamer, como vimos, empleaba la metáfora de la fusión para explicar la naturaleza misma de la comprensión. Hemos aquí empleado la metáfora también para explicar cómo es posible aproximar dos horizontes culturales distantes. En el caso de Quebec, esos horizontes culturales se encuentran conviviendo de forma conjunta. Para que puedan ser fusionados, son necesarias políticas sociales adecuadas. Que tenga lugar la comprensión intercultural depende, por tanto, de la voluntad de los políticos y también de la de los ciudadanos. Hemos demostrado que es posible esa comprensión, pero la realización de 
esa comprensión en la praxis depende siempre de los sujetos comprensores, que en este caso son los ciudadanos que conviven en una sociedad multicultural.

Es algo connatural a los horizontes la fusión con otros. Depende de quienes se encuentran comprendidos bajo esos horizontes que la fusión tenga lugar de un modo o de otro, con unos horizontes o con otros. Por ello, es imprescindible realizar una labor como la que ha llevado a cabo la Comisión Bouchard-Taylor. Sin una propuesta sociopolítica que dirija la fusión de los horizontes culturales no es posible garantizar que ésta tenga lugar. Por supuesto, no es necesario que existan políticas multiculturales que promuevan la interculturalidad para que la fusión de horizontes culturales se produzca. Hay sociedades multiculturales en las que tiene lugar de suyo la comprensión intercultural. Pero cuando se dan dificultades en la convivencia de esos ciudadanos de una sociedad multicultural que impiden que acontezca la comprensión intercultural, como ha ocurrido en Quebec, las políticas sociales son imprescindibles.

Por ello, la promoción de la interculturalidad mediante políticas sociales no es sino el paso siguiente a la demostración de que es posible la comprensión intercultural. De ahí que la hermenéutica intercultural y los estudios sociopolíticos sobre la interculturalidad sean complementarios. Así lo hemos mostrado en el caso particular del pensamiento de un autor como Taylor, que ha cultivado ambos lados. Con ello no ha hecho sino llevar al terreno de la filosofía de la cultura lo que Gadamer había elaborado como una nueva perspectiva filosófica. Taylor ha mostrado que la hermenéutica tiene gran potencial para pensar los fundamentos de las propuestas políticas que promueven la interculturalidad.

Una de las ideas fundamentales de la hermenéutica de Gadamer -la de que nosotros, desde nuestros propios horizontes, "podamos no tener razón", concediendo así la posibilidad de que el otro la tenga-, es clave para la construcción de una hermenéutica intercultural, en la que el principio rector es la escucha del otro, el intento de comprender al otro en sus propios términos sin abandonar los nuestros. Se trata de ampliar nuestra comprensión mediante la comprensión del otro, 
mediante la asimilación en nuestra comprensión de los términos de la autocomprensión que tiene el otro, y viceversa: que el otro llegue a comprender en los términos de nuestra autocomprensión sin abandonar la suya propia.

Una de las conclusiones más importantes que cabe extraer de la presente investigación es, por tanto, que la hermenéutica no es únicamente una teoría filosófica que verse sobre el fenómeno de la interpretación a una escala "especulativa" o "teórica", sino que también sirve para estudiar los problemas de carácter social y político.

Los problemas filosófico-prácticos -es decir, los problemas políticos, económicos, sociales, culturales, éticos, etcétera, según la clasificación aristotélica de los saberes ${ }^{46}$ - pueden ser comprendidos también hermenéuticamente. El propio Gadamer ha dedicado parte de sus investigaciones hermenéuticas a la noción de razón práctica ${ }^{47}$ y a la naturaleza de los problemas filosófico-prácticos. La hermenéutica filosófica contiene en sí misma el potencial de la comprensión de los problemas que surgen a raíz de los cambios económicos, políticos, sociales y culturales que han tenido lugar en los últimos años. El estudio del caso de Quebec nos ha permitido, en particular, centrarnos en el problema de las normas de carácter no jurídico con que armonizar las diferentes cosmovisiones de los ciudadanos.

En este sentido, la hermenéutica, en particular cuando es aplicada a casos de conflictos originados por la diversidad cultural, que implica una diversidad de creencias, de prácticas y de interpretación del significado de los símbolos, es una herramienta conceptual de gran relevancia.

Los conflictos multiculturales son con frecuencia alimentados por el hecho de que no hay un fondo común compartido de pre-juicios y horizontes. Frente a quienes defienden que tales conflictos son

46 ARISTÓTELES. Ética a Nicómaco, Centro de Estudios Políticos y Constitucionales, Madrid, 1985, libro VI.

47 Cf. GADAMER, H.-G. Verdad y método II, Sígueme, Salamanca, 1991, cuarta parte. 
inevitables, hemos mostrado, junto a Gadamer, Bouchard y Taylor, que no existen razones para que se originen o sigan en activo. La promoción de la convivencia armónica entre individuos de distintas culturas tiene fundamentos que el etnocentrismo nunca nos puede hacer olvidar.

\section{Referencias bibliográficas}

ARISTÓTELES. Ética a Nicómaco, Centro de Estudios Políticos y Constitucionales, Madrid, 1985.

BOUCHARD, G. y TAYLOR, Ch. Building the Future. The Time of Reconciliation. Abridged Report, Bibliothèque et Archives nationales du Quebec, Quebec, 2008 (versión castellana: Construir el futuro. El tiempo de la reconciliación, Observatorio vasco de inmigración, Gipuzkoa, 2010).

CONILL, J. Ética hermenéutica, Tecnos, Madrid, 2006.

CORTINA, A. Ética mínima, Tecnos, Madrid, 1990.

DERRIDA, J. De la gramatología, Siglo XXI, México, 1995.

DILTHEY, W. Introducción a las ciencias del espíritu, Alianza, Madrid, 1981.

DOMINGO MORATALLA, A. El arte de poder no tener razón. La hermenéutica dialógica de H.-G. Gadamer, Universidad Pontificia, Salamanca, 1991.

GADAMER, H.-G. Verdad y método I, Sígueme, Salamanca, 1987. Verdad y método II, Sígueme, Salamanca, 1991.

GRACIA, J. "El encuentro intercultural en la hermenéutica de Charles Taylor", Diálogo Filosófico, № 64, 2005, págs. 77-94.

Antropología filosófica en Charles Taylor. Perfil hermenéutico del ser humano, EAE, Saarbrücken, 2011.

GRONDIN, J. Introducción a Gadamer, Herder, Barcelona, 2001.

HABERMAS, J. Los intereses del conocimiento, PUV, Valencia, 1999.

KAGAN, J. The Three Cultures, Cambridge University Press, Cambridge, 2009.

LAPORTA, F. J. "Ética y política", en Claves de razón práctica, № 2, 1990, pp. 15-21.

SALAS ASTRAÍN, R. Ética intercultural, Ediciones UCSH, Santiago de Chile, 2003. 
TAYLOR, Ch. La libertad de los modernos, Amorrortu, Madrid, 2005.

El multiculturalismo y la política del reconocimiento", en GUTMANN, A. (ed.), El multiculturalismo y la política del reconocimiento, FCE, México, 1993.

TRÍAS, E. "Identidad cultural", en ConILL, J., Glosario para una sociedad intercultural, Bancaja, Valencia, 2002. 